\title{
Examination of Energy Resolution of Track Detector LR-115 to Distinguish the Various Energies of Alpha Particles (1-4MeV) Using the Wblfit formula Fitting in Matlab Software
}

\author{
*Firas M. Al-Jomaily Malik H. Kheder Hala I. Jasim \\ Department of Physics/ College of Science/ University of Mosul \\ *Email: aljomaily16@gmail.com
}

(Received 20/2/2014; Accepted 5/5/2014)

\begin{abstract}
This study aims to test energy resolution of the nuclear track detector LR-115 to distinguish the various energies of alpha particles $(1-4 \mathrm{MeV})$ that were obtained from radioactive isotope ${ }^{241} \mathrm{Am}$. This method is based on the relationship between the energy deposited in the material by ionizing particles and the track developed after a well-established chemical process $\left(\mathrm{NaOH}, 2.5 \mathrm{~N}, 60^{\circ} \mathrm{C}\right)$. Solid state nuclear track detectors (SSNTD's) have been used successfully as detecting devices and as a passive system to detect alpha contamination on different surfaces. The resulted tracks are performed with a digital image analysis system (image processing) associated with a PC mathematical processor and the track diameter distribution fitted by wblfit formula. The mean track diameter (D) for each used energy, its width $\Delta \mathrm{D}$ at full width at half maximum (FWHM)and energy resolution power $(\Delta \mathrm{E} / \mathrm{E}) \mathrm{D}$ were measured for each neighboring energies. The results of energy resolution of LR-115 were compared with results of another nuclear track detectors of similar studies at average energy (3.7 MeV).
\end{abstract}

Keywords: Isotope identification ; Nuclear tracks ; LR-115 ; Energy resolution.

\section{الختبارقرة التحلال الالف لكلثف الثر LR-115 للتمييز بينطلات جسيمل ألفاضصن المدى (1-4MeV) بلستخدلم الملاعمة بصيغة ويل في مجموعة برامج مالنالب}

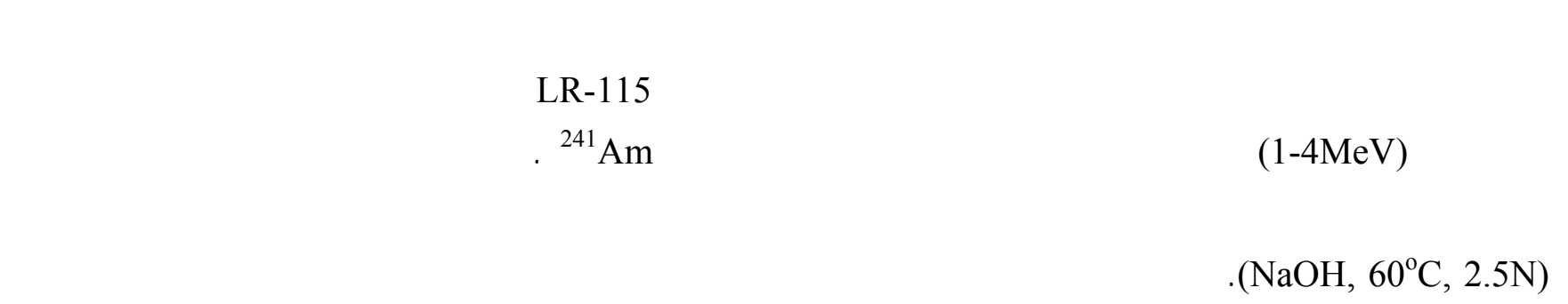
تبعث جسيملت ألفا وعدها عناصرر ملوثة. مّ لظهار الآثار المتخلفة على مادة الكلثف من خلل ظلم رقمي و تحليلي (معالجة صورية) للأسطح كلثف الأثر النووي الذي م إعداهه بلغة ماتلاب وسمي بلهم (Wb1 Track). لجريت ملاعمة من خلال صيغة توزيع ويل على لطيف التوزيع لعلاقة مكررات الآثارطقا لأفطارها. قيهت معدلات أتطار الآثار (D) لل طلاقة مستخدة فضلا عن معدلات عرض الذروة (BD) عند منتصف أعلى ارتقاع (FWHM). حددت قدرة التحليل الطاقي بدلالة التطر (AE/E)D

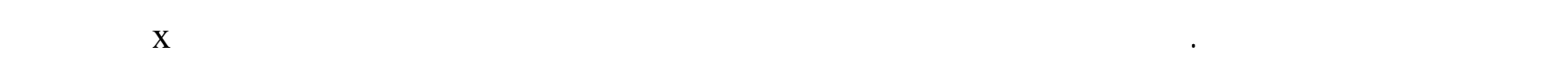


طجاقة يقتربم من (3.7MeV).

الكالت الدالة : تشخيص الظائر، الآثار النووية، الكلثف LR-115، التحليل الطالي.

INTRODUCTION

As is well known, by making use of the relationship between the etching track parameters and the energy deposited in nuclear track detectors, different alpha particles can be identified (Espinosa and Moreno, 1979), (Ilic et al., 1993).

The nuclear track detectors can be used successfully as detecting devices for radon, uranium, neutrons and heavy ionizing particle interaction with matter (Tawfiq et al., 2013), (Babai et al., 2012), (Noori and Ranjbar, 2012), (Najam et al., 2011)

A possible use of plastics such as LR-115 has been explored to monitor low-level alpha particle contamination of solid surfaces. These detectors can be placed in contact with the surfaces to be tested for contamination. The fundamental physical phenomenon is the deposition of alpha particle energy in a cellulose nitrate and the formation of a cone along the particle trajectory in the material after a specific chemical process. The cone thus formed is determined by the relationship between its geometrical size and the energy deposited (Dorschel et al., 2003).

The theoretical and experimental investigations of the penetration of charged particles in matter played a very important role in the development of modern physics. Solid state nuclear track detectors have became one of the most important tools for many branches of science and technology, for example, in neutron dosimetry, gamma and cosmic rays detection, heavy ion and nuclear physics and corpuscular diagnostics in high-temperature plasma experiments. The passage of heavy charged particles through most insulators leads to the formation (at the micro-structural level) of narrow regions of radiation-damaged matter; referred to as latent tracks (Durrani and Bull, 1987), (Fleischer et al., 1975), (Tanner, 1980).

There is a method presents advances in a procedure for alpha particle analysis using the nuclear tracks formed in solid-state materials. This method is based on the relationship between the energy deposited in the material by ionizing particles and the track developed after a well-established chemical process. The experimental study included alpha particles in the energy range from 3.2 to $5.8 \mathrm{MeV}$ emitted by Gd-148, U-238, Pu-239 and Cm-244 (Amero et al., 2001).

Another study presents the response of CR-39 (for two types) to alpha particles from two sources, ${ }^{238} \mathrm{Pu}$ with energy $5 \mathrm{MeV}$ and ${ }^{241} \mathrm{Am}$ with energy $5.4 \mathrm{MeV}$, the methods of etching and counting are investigated, along with the achievable linearity, efficiency and reproducibility. The sensitivity to low activity and energy resolution are studied (Zaki and El-Shaer, 2007).

This work is focused on the procedure for analysis of alpha particles using nuclear track detectors LR-115 which was supplied by Preshore Mouldings, Ltd., UK. The automatization of the data analysis was done to find the track diameter distribution of the radioisotope and corresponding energies in order to determine the energy resolution of LR-115.

\section{1- Sample Preparation}

\section{EXPERIMENTAL DETAILS}

LR-115 detector was used in which it was covered with $1000 \mu \mathrm{m}$ paper. This protection layer cover protects the detector material from interaction with radon during the transport and storage of the 
LR-115. This protection layer is removed once the process is started . For this work, we have selected the polymer commercially named LR-115 ( cellulose nitrate) with thickness $12 \mu \mathrm{m}$.

\section{2- Alpha Particles Irradiation}

Irradiation was performed in air using ${ }^{241} \mathrm{Am}$ alpha source with different energies $1,1.5,2,2.5$, $3.5,4 \mathrm{MeV}$, with a $1 \mathrm{~mm}$ aluminum collimator placed between, the detector and the source. For reading we used only normal incidence alpha particles on the material detector. In this work we propose a single step chemical etching, this process is optimized, using a ( $2.5 \mathrm{~N}$ ) NaOH solution at 60 $\pm 0.1^{\circ} \mathrm{C}$. The chemical etching process for different time intervals was studied .

\section{Energy resolution}

In this experiment, we need to express the energy as a function of the diameter $\mathrm{E}(\mathrm{D})$. The displacement $\Delta \mathrm{E}$ is carried out by means of the chain rule of the calculus (Thomas and Finney, 1992).

$$
\Delta \mathrm{E}=(\Delta \mathrm{E} / \Delta \mathrm{D}) . \Delta \mathrm{D}
$$

Equation (1) can be written in a different form by using the approximation

$$
\Delta \mathrm{E} / \Delta \mathrm{D}=(\mathrm{E} 2-\mathrm{E} 1) /(\mathrm{D} 2-\mathrm{D} 1)
$$

As a consequence of this approach, eq. (1) takes the form

$$
(\Delta \mathrm{E} / \mathrm{E}) \mathrm{D}=[(\mathrm{E} 2-\mathrm{E} 1) / 0.5(\mathrm{E} 2+\mathrm{E} 1)] *[\Delta \mathrm{D} /(\mathrm{D} 2-\mathrm{D} 1)]
$$

This equation can be illustrated in Fig. (1).

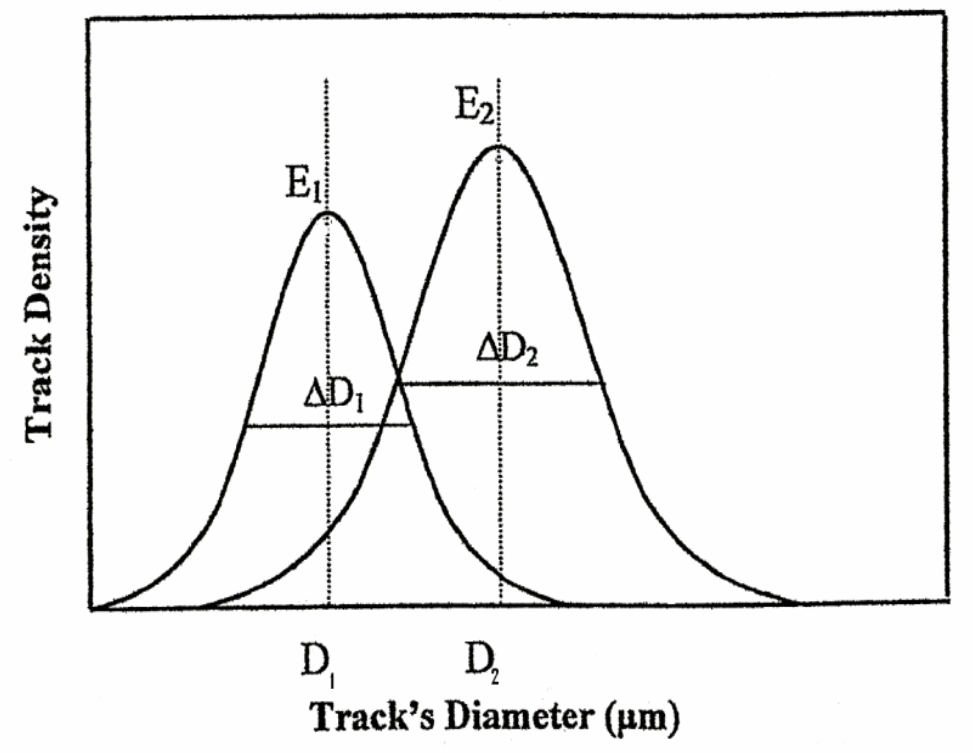

Fig. 1: Distribution spectrum of tracks density corresponding to tracks diameter

Where E1 and E2 are the energies of incident alpha particles, D1 and D2 are the mean track diameters corresponding to each energy and $\Delta \mathrm{D}$ is the width of the diameter distribution(FWHM). D1, D2 and $\Delta \mathrm{D}$ are determined by fitting the data for the track size distribution. This process was performed by a program which was written in matlab language for image processing of surface detector (digital system) that can be used to determine some of the nuclear parameters as mentioned 
above .The diameter distribution was fitted by wblfit (for fitting many different parametric distributions using maximum likelihood). Weibull PDF takes the form (Devroye,1986).

$$
y=(a / b) .(x / a)^{(b-1)} \cdot \exp \left(-(x / a)^{b}\right)
$$

Where $\mathrm{a}$ and $\mathrm{b}$ are constant parameters.

This is almost the same functional form as the Weibull curve used in the curve fitting. However, there is no separate parameter to independently scale the vertical height. Being a PDF, the function always integrates to 1 . The Weibull curve we're using, just like other similar models such as Gaussian, gamma, or exponential curves (Devroye,1986).

\section{RESULTS AND DISCUSSION}

Experimentally, it was observed that the track diameter distribution has a displacement along the $x$ axis as a function of the etching time. For each etching time, from 90 to 150 min, a wblfit of the track distribution was made and the standard deviation calculated. The minimum value of the standard deviation was found for $105 \mathrm{~min}$ of chemical etching. Using this time as the optimum one, the wblfit to track diameter distribution for different energies is shown in Figs. (2,a,b,c,d,e,f).

The energies are identified as a function of the track diameter. To determine the response of the nuclear track detectors, the energies are plotted against the mean value of the respective track diameter . The response is linear corresbonding to the fitting equation $(\mathrm{Y}=-1.1266 \mathrm{x}+10.301)$ with $\mathrm{R}^{2}=0.8945$, in this case from 1 to $4 \mathrm{MeV}$, as seen in Fig. (3). Using the track diameter distribution and the mean value and standard deviation as obtained from the wblfit, the energy resolution for different alphaenergies are calculated using eq. (3). The results are shown in table 1. Fig. (4) illustrates the inverse proportion between energy resolution and energy of alpha particles. To obtain the track diameter distribution, for each one of the energies, the following considerations were taken: (a) The circular tracks where the relationship of minor $\mathrm{d}$ and major $\mathrm{D}$ diameters $(\mathrm{d}=\mathrm{D})$ is between 0.9 and 1.0 are counted (Espinosa et al.,1996); (b) only the major diameter was considered for the analysis. With these two restrictions, the measurements were done for different etching times from 90 to $150 \mathrm{~min}$, for a period of $15 \mathrm{~min}$ of each. From this experiment it was observed that the diameter distribution histogram dose move along the $\mathrm{x}$-axis as function of the etching time and energy of alpha particle. A wblfit analysis of the track distribution for each etching time of the detectors was made, obtaining that the lowest value of the standard deviation is for 105 min of etching.

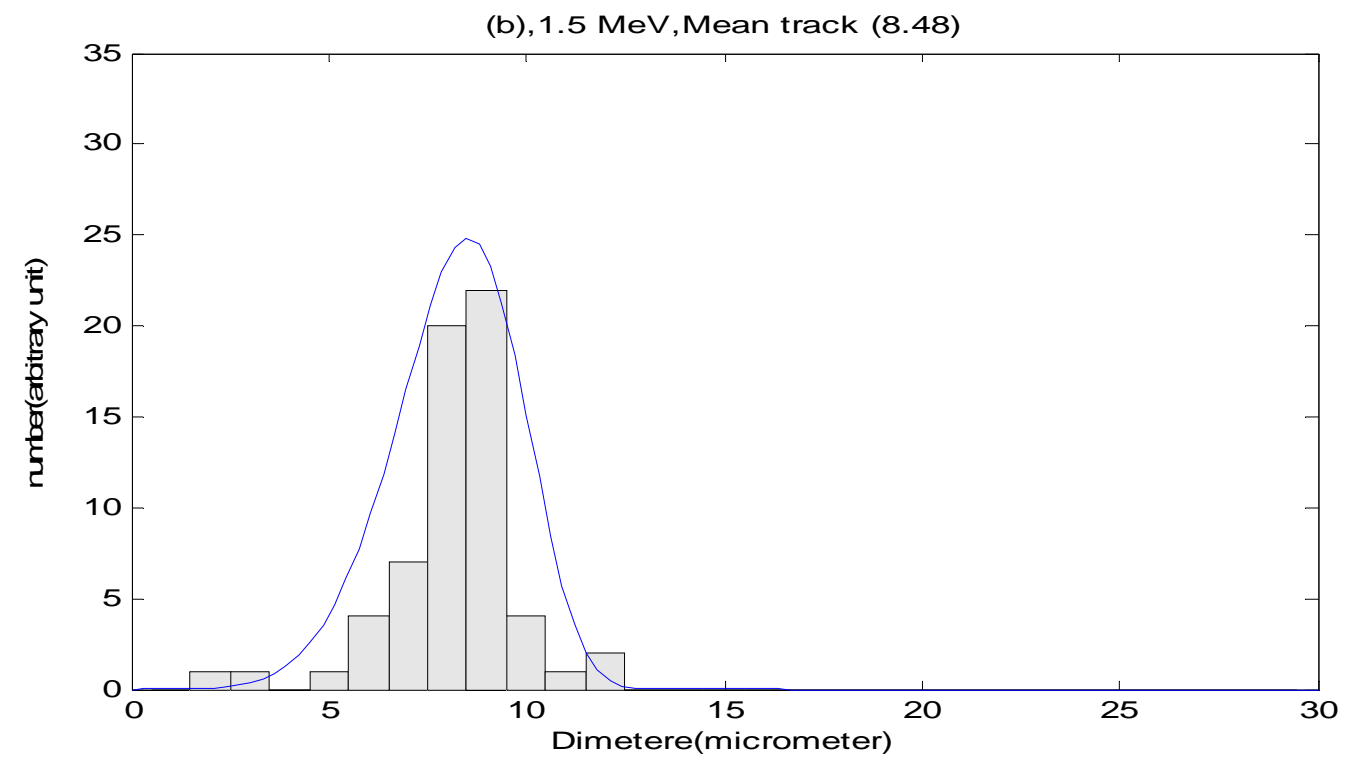



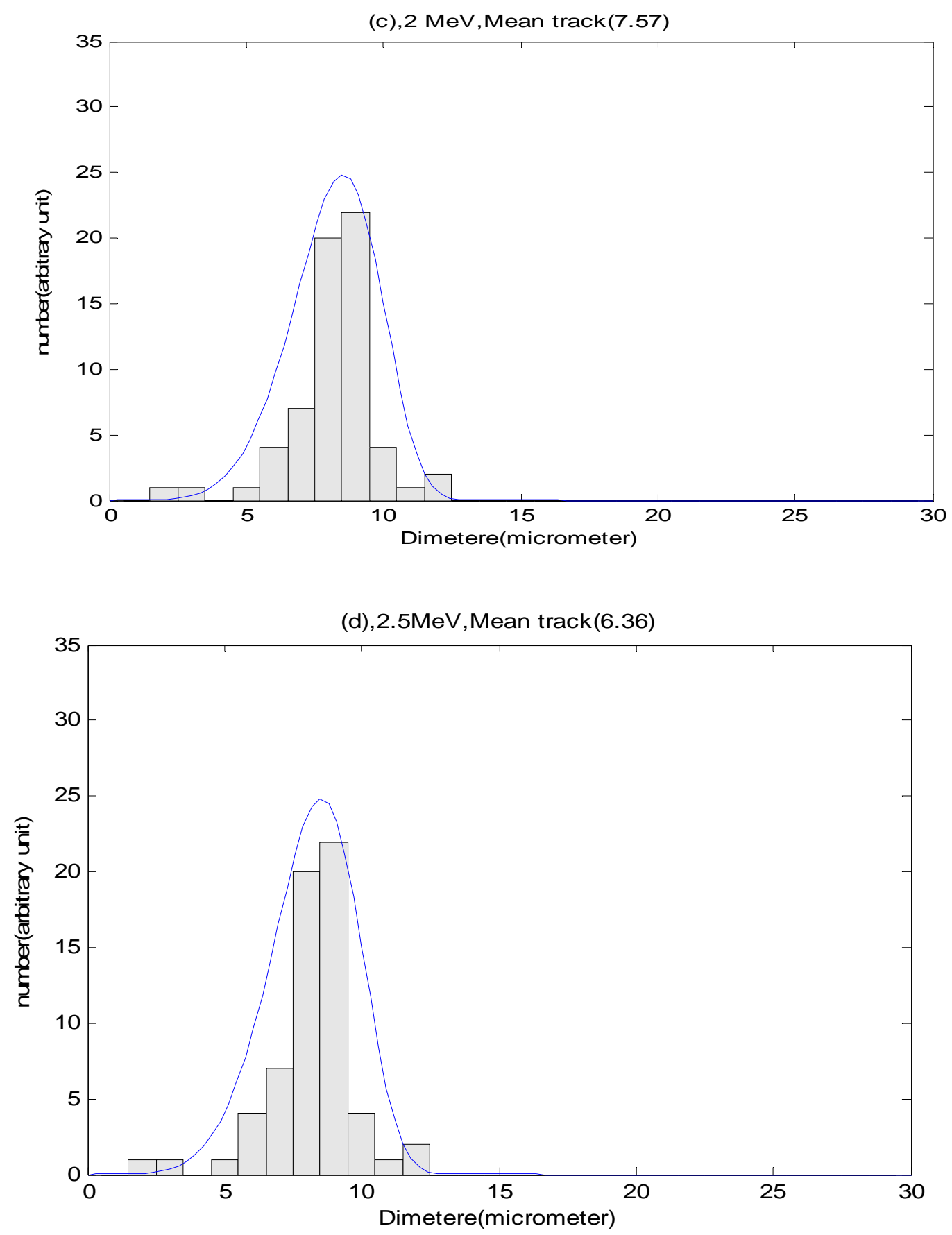
(e), 3.5MeV, Mean $\operatorname{track}(4.84)$
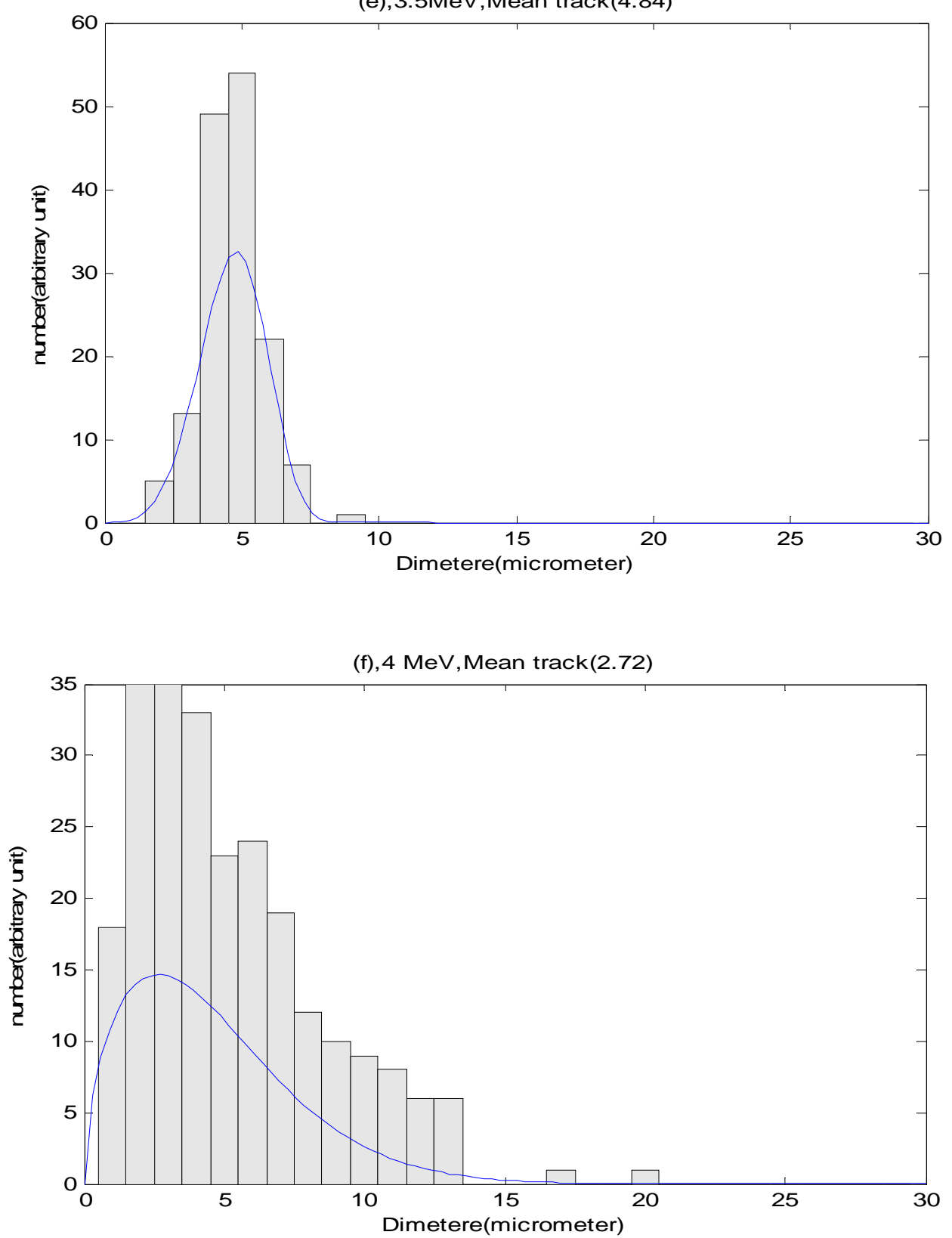

Fig. 2: Track diameter distribution and wblfit for each energy (a,b,c,d,e,f) of the ${ }^{241} \mathrm{Am}$ alpha source. 


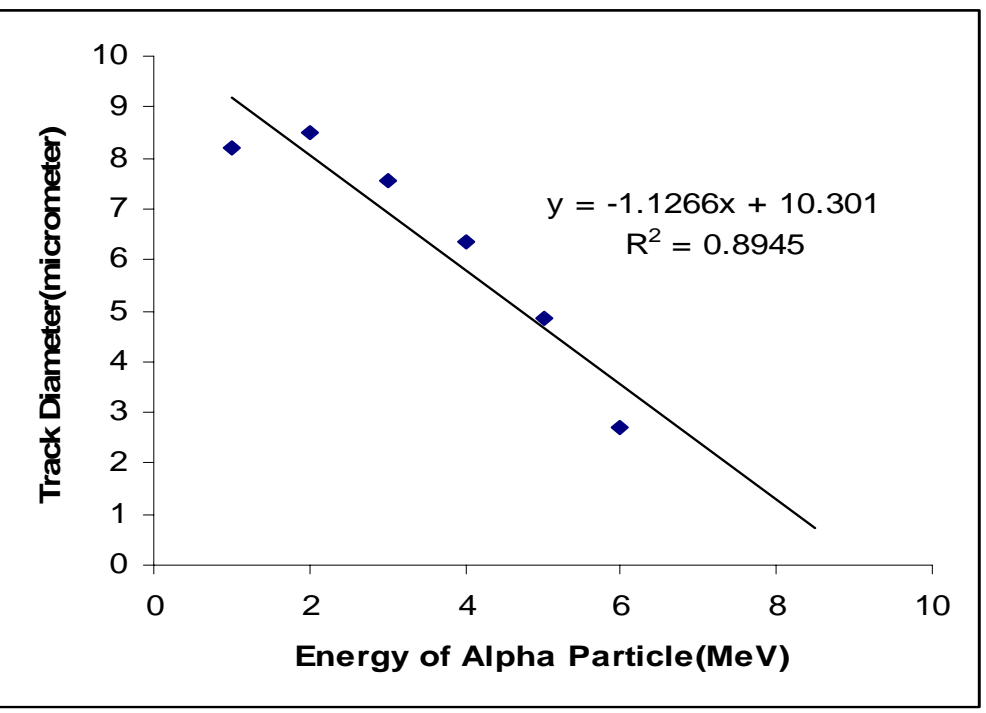

Fig. 3: Track diameter as afunction of Alpha particle energy

Table 1 : Mean track diameter (D) for alpha particle energies after $105 \mathrm{~min}$ of etching time and the data for the energy resolution.

\begin{tabular}{|c|c|c|c|c|}
\hline $\begin{array}{c}\text { Energy } \\
(\mathbf{M e V})\end{array}$ & $\begin{array}{c}\text { Mean Track } \\
\text { Diameter(D) }\end{array}$ & $\begin{array}{l}\text { Standard } \\
\text { Deviation }\end{array}$ & $\Delta \mathbf{D}$ (FWHM) & Energy Resolution \\
\hline 1 & 8.18 & 1.41 & 3.33 & \\
\hline 1.5 & 8.48 & 1.44 & 3.33 & 2.22 \\
\hline 2 & 7.57 & 2.05 & 4.84 & 0.6413 \\
\hline 2.5 & 6.36 & 1.54 & 3.63 & 0.3889 \\
\hline 3.5 & 4.84 & 1.158 & 2.72 & 0.3505 \\
\hline 4 & 2.72 & 2.574 & 6.06 & 0.1381 \\
\hline
\end{tabular}

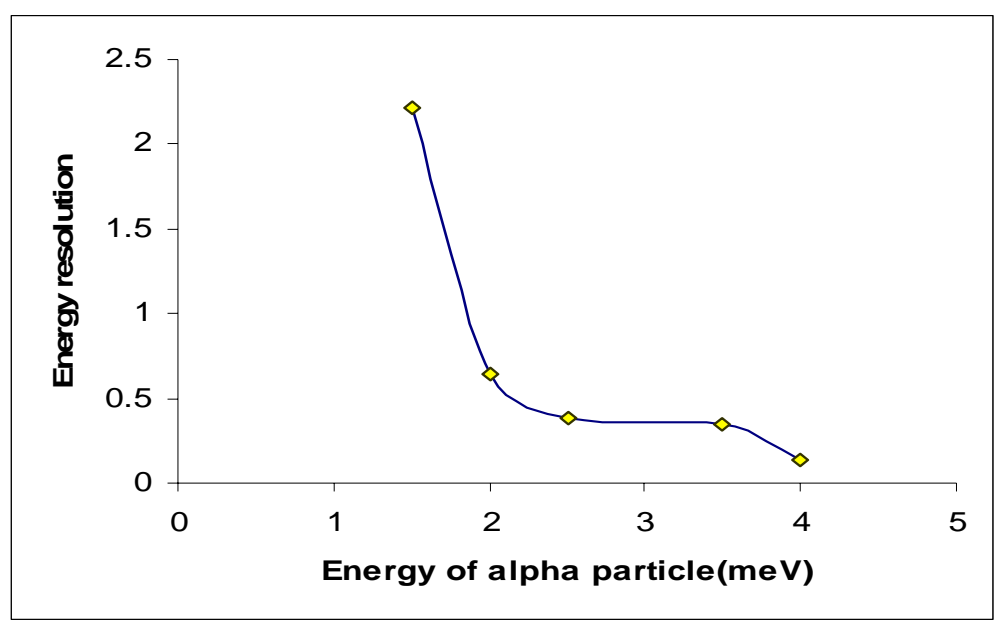

Fig. 4: Energy resolution versus Energy of alpha particles 
Comparison the energy resolution of LR-115 at specific energy of alpha particle with other nuclear track detectors will be illustrated through the following Table(2) .

Table 2 : Comparison of energy resolution of different nuclear track detectors at specific energy of alpha particle.

\begin{tabular}{|l|l|l|l|}
\hline References & Detector & Specific Energy of $\alpha$ - Particle & Energy Res. \\
\hline Zaki and El- Shaer,2007 & CR-39 & 3.7 & 0.1794 \\
\hline Amero et al.,2001 & CR-39 & 3.7 & 0.18 \\
\hline AL-jobouri ,2004 & PM-355 & 3.87 & 0.54 \\
\hline Present Work & LR-115 & 3.7 & 0.13 \\
\hline
\end{tabular}

This table reveals that the energy resolution of LR-115 better than the other nuclear track detectors at same energy of alpha particle.

\section{CONCLUSION}

* The nuclear track detectors can be very useful for alpha energy analysis and as a particularization of alpha contamination.

* Digital image analysis systems by using wblfit formula, are very helpful to measure automatically, the track diameter distribution and fast procedure for the alpha particle energy identification.

* Being the nuclear track methodology, it is considered as another option for alpha spectroscopy with a reasonable resolution and cost.

* The results showed an inverse proportion between energy resolution of LR-115 detector and energy of alpha particles.

\section{REFERENCES}

AL-Jobouri, M. M. S. (2004). Energy Resolution Power of The Plastic Nuclear Track Detector PM355 for Alpha Particles and the Effect of the Heating Treatment. Thesis in Mosul University ,Mosul, Iraq, Education College

Amero, C.; Golzarri, J. I.; Izerrouken, M.; Espinosa, G. $(2001) .{ }^{148} \mathrm{Gd},{ }^{238} \mathrm{U},{ }^{239} \mathrm{Pu}$ and ${ }^{244} \mathrm{Cm}$ alpha particle energy analysis using tracks in solids. Radiation Measurements 34, 341-343.

Babai, K.S.; Poongathai, S.; Lakshmi, K.S.; Punniyakotti, J.; Meenakshisundaram, N. (2012). Estimation of indoor radon and absorbed dose rates in air for chennai city, Tamilnadu, India. $J$. Radioanal. Nucl. Chem. 293, 649-654.

Devroye, L. (1986).” Non-Uniform Random Variate Generation”. New York: Springer-Verlag.

Dorschel, P.B.; Hermsdorf, D.; Pieck, S.; Starke, S.; Thiele, H.; Weickert, F. (2003). Studies of SSNTD's Made From LR-115 in View of their applicability in radiobiological experiments with alpha particles . Nuclear Instruments and Methods in Physics Research, B 207, 154-164.

Durrani, S.A.; Bull, R.K. (1987). “ Solid State Nuclear Track Detection: Principles, Methods and Applications". Pergamon Press, Oxford, UK.

Espinosa, G.; Moreno, A. (1979). "Alpha detection by SSNTD’s. Proceedings of the 10th International Conference on SSNTD". Lyon, France. Academic Press. New York, pp. 777-784. 
Espinosa, G.; Gammage, R.B.; Meyer, K.E.; Dudney, C.S. (1996). Nuclear track analysis by digital imaging. Radiat. Prot. Dosim.66, 363-366.

Fleischer, R.L.; Price, P.B.; Walker, R.M. (1975). " Nuclear Tracks in Solids - Principle and Applications". University of California, Berkeley, California .

Ilic, R.; Sutej, T.; Skvarc, J.; Humar, M. (1993). Current research on nuclear track in solids . Nucl. Tracks Radiat. Meas. , 21, 397-403.

Najam, L.A.; Al-jomaily, F.M.; Al-farha, E.M. (2011). Natural radioactivity levels of limestone rocks in northern Iraq using gamma spectroscopy and nuclear track detector. J. Radioanal. Nucl. Chem., 289, 709-715.

Noori, H.; Ranjbar, A.H. (2012). Radon health hazards of some rocks of iranian origin, frequently used as building stones. J. Radioanal. Nucl. Chem., 290, 183-186.

Tanner, A.B. (1980). "Radon Migration in the Ground; A Supplementary Review". Rep. CONF7H0422, US Dept. of Energy, Washington DC 1, pp. 5-56.

Tawfiq, N.F.; Ali, T.L.; Al-Jobouri, H. (2012). Uranium concentration measurements in human blood for some governorates in iraq using CR-39 track detector. J. Radioanal. Nucl. Chem., 295, 671674.

Thomas, G. B.; Finney, R.L. (1992).” Calculus and Analytical Geometry”. 8th edn. Addison, Wesley, London.

Zaki, M.F.; El-Shaer, Y.H. (2007). Particularization of Alpha contamination using CR-39 track detectors. PRAMANA J. Physics (Indian Academy of Sciences). 69(4), 567-574. 